\title{
Burnout experience among nurses and self - reported quality of care in Osun State tertiary hospitals
}

\author{
Ayandiran E.O. ${ }^{1}$, *Akinyoola O.O. ${ }^{2}$, Ajao O.O. ${ }^{2}$, Chibe O.G. ${ }^{3}$
}

\begin{abstract}
Objectives: Burnout is a feasible phenomenon among healthcare professionals, including nurses. The consequence is reduction in their overall efficiency and therefore can affect the quality of care they render to patients. The study examined the influence of burnout experience on nurses - reported quality of nursing care in Tertiary hospitals in Osun state.
\end{abstract}

Methods: A descriptive, cross-sectional design was used to study 230 randomly selected nurses working in admission facilities of tertiary hospitals in Osun state. Data was collected with semi structured questionnaire adapted from Maslach Burnout Inventory and Karen - personnel instrument for measuring quality. Kruskal - Wallis $\mathrm{H}$ tests of association were done at 0.05 significance level.

Results: The study revealed a statistically significant association between Burnout experiences and nurse - reported quality of nursing care in the hospitals studied $\left(\chi^{2}=14.46, p=0.006\right)$.

Conclusion: Burnout experience affected the Self - reported quality of nursing care in the facilities studied.

Keywords: Burnout experience, Self-reported quality of nursing care.

\author{
*Corresponding Author \\ Akinyoola, O.O. \\ http://orcid.org/0000-0001-6303-6922 \\ Email: deleakinyoola@yahoo.com \\ ${ }^{1}$ Department of Nursing, Obafemi Awolowo University, Ile - Ife, Osun state, Nigeria \\ ${ }^{2}$ Department of Nursing, Osun State University, Osogbo, Osun State, Nigeria \\ ${ }^{3}$ Department of Nursing Services, Babcock University Teaching hospital, Ilishan - Remo, Ogun State, Nigeria
}

Research Journal of Health Sciences subscribed to terms and conditions of Open Access publication. Articles are distributed under the terms of Creative Commons Licence (CC BY-NC-ND 4.0). (http://creativecommons.org/licences/by-nc-nd/4.0).

http://dx.doi.org/10.4314/rejhs.v6i4.6 


\title{
Expérience de burnout chez les infirmières et qualité de soins autodéclarée dans les hôpitaux tertiaires de l 'État d' Osun
}

\author{
Ayandiran E.O. ${ }^{1}$, *Akinyoola O.O. ${ }^{2}$, Ajao O.O. ${ }^{2}$, Chibe O.G. ${ }^{3}$
}

\section{Resume}

Objectifs: L'épuisement professionnel est un phénomène réalisable chez les professionnels de la santé, y compris les infirmières. La conséquence est une réduction de leur efficacité globale et peut donc affecter la qualité des soins qu'ils rendent aux patients. L'étude a examiné l'influence de l'expérience d'épuisement professionnel sur le personnel infirmier - la qualité déclarée des soins infirmiers dans les hôpitaux tertiaires de l'État d'Osun.

Méthodes: Un plan descriptif transversal a été utilisé pour étudier 230 infirmières sélectionnées au hasard et travaillant dans les installations d'admission des hôpitaux tertiaires de l'État d'Osun. Les données ont été collectées à l'aide d'un questionnaire semi-structuré adapté de Maslach Burnout Inventory et de l'instrument de mesure du personnel Karen destiné à mesurer la qualité. Les tests d'association Kruskal Wallis $\mathrm{H}$ ont été effectués à un niveau de signification de 0,05 .

Résultats: L'étude a révélé une association statistiquement significative entre les expériences d'épuisement professionnel et la qualité des soins infirmiers déclarée par les infirmières dans les hôpitaux étudiés $(\chi 2=14,46, p=0,006)$.

Conclusion: L'expérience d'épuisement professionnel a eu une incidence sur la qualité des soins infirmiers autodéclarée dans les établissements étudiés.

Mots clés: expérience de surmenage, qualité autodéclarée des soins infirmiers.

\footnotetext{
* Auteur de la correspondance

Akinyoola, O.O.

http://orcid.org/0000-0001-6303-6922

Email: deleakinyoola@yahoo.com

${ }^{1}$ Department of Nursing, Obafemi Awolowo University, Ile - Ife, Osun state, Nigeria

${ }^{2}$ Department of Nursing, Osun State University, Osogbo, Osun State, Nigeria

${ }^{3}$ Department of Nursing Services, Babcock University Teaching hospital, Ilishan - Remo, Ogun State, Nigeria
}

Research Journal of Health Sciences subscribed to terms and conditions of Open Access publication. Articles are distributed under the terms of Creative Commons Licence (CC BY-NC-ND 4.0). (http://creativecommons.org/licences/by-nc-nd/4.0).

http://dx.doi.org/10.4314/rejhs.v6i4.6

Res. J. of Health Sci. Vol 6(4), Oct./Dec., 2018 


\section{INTRODUCTION}

Work is a significant and meaningful part of life. It provides individuals with structures, purpose, satisfaction, self esteem and spending power. Most adults spend about $25 \%$ of their lives working (1). Work situations however present myriads of challenges which constitute stressors. Positive resolution of these stressors leads to sense of satisfaction fostering motivation and well-being. Moreover, exposure to prolonged, unresolved work demands can overwhelm the worker and consequently affect his overall wellbeing. This condition may present as feelings of emotional exhaustion, depersonalization and reduced personal accomplishment hence burnout experience (2). Burnout is a psychological syndrome due to prolonged exposure to high job demands as a result of stressful working environment without the commensurate support resources (3).

Nurses are pivotal in the operation of healthcare services; they attend to individual patient's need such as helping them assess their condition, answering their questions and in many instances, giving medications or treatments as well as assisting patients go through medical procedures (4). However, the term quality is a complex and multi-dimensional concept especially within the context of healthcare, where it has been shaped by organizational, patient and societal expectations (5). Quality in nursing care however has been defined as nurse - patient interactions based on advocacy, caring, empathy, intentionality and respect (6). Attaining quality in the setting of nursing care could necessitate working tirelessly round the clock to promote patients recovery and safety as well as satisfy organizational, patient and societal expectations (6). Consequently, clinical nursing practice generally has been perceived as stressful (7) due to its characteristic high job demands such as shift work, frequent night shifts, long working hours spent with patients with complex demands such as debilitated and dying patients, high workloads due to inadequate nursing personnel and working within complex organizational setting often with conflicting mission $(2,7)$. Nurses consequently are more vulnerable to experiencing burnout and factually have been documented to experience high levels of burnout syndromes (7). The possible consequence is burnout experience, and its attendant significant negative effect on job performance (8) for instance, higher medical errors and sub - optimal care quality (9). The experience can therefore hamper patients' recovery process.
In Nigeria, high level of burnout syndrome has been documented among clinicians working within various admission facilities of the hospital, (7) however no published evidence has investigated the influence of nurses' burnout experience on the quality of nursing care rendered. The study therefore examined the influence of burnout experience on the nurses - reported quality of nursing care in tertiary hospitals in Osun state.

\section{METHODS}

Research design and Settings: A descriptive cross sectional method with quantitative approach was used to study burnout experience and quality of nursing care among nurses in Obafemi Awolowo University Teaching hospitals complex (OAUTHC) and Seventh Day Adventist hospital (SDAH), Ile - Ife, Osun state. Both study sites provide tertiary level healthcare services to population within Osun State and neighboring states within south west Nigeria. OAUTHC is funded by federal government of Nigeria while SDAH is a private facility, owned and managed by the Seventh Day Adventist church, Nigeria.

Research Participants: These included all cadres of registered nurses working within all the admission facilities but the out - patient settings of the study sites. Therefore, the total population of nurses eligible for the study in OAUTHC and SDAH were 538.

Sample size: This was determined to be 230 nurses using Taro - Yammane formula for sample size calculation (10).

where;

$$
\mathrm{n}=\mathrm{N} / 1+\mathrm{N}\left(\mathrm{e}^{2}\right)
$$

$\mathrm{N}=$ population size (538 nurses)

$\mathrm{n}=$ sample size

$\mathrm{e}=$ sampling error which was taken to be 0.05 $(5 \%)$

$$
\begin{aligned}
& \mathrm{n}=538 / 1+538(0.05)^{2} \\
& \mathrm{n}=230
\end{aligned}
$$

Sampling technique: The ratio of nurses in OAUTHC to SDAH was approximately $3: 1$. Therefore 154 and 76 samples were randomly selected from OAUTHC and SDAH respectively. The admission facilities within OAUTHC were classified into adult and pediatric facilities. These were further stratified into the medical and surgical units. The adult medical and surgical units were divided into the female and male sections. Therefore 25 nurses each were selected from the male medical, male surgical, female 
medical and female surgical wards while 27 nurses each was selected from the pediatric medical and pediatric surgical wards. The admission facility in SDAH was divided into medical, surgical and pediatric units. 25 nurses each were selected from the medical and pediatric units while the remaining 26 nurses were selected from the medical unit. The sample nurses were selected by a simple random technique.

Research Instruments: Data were collected with one instrument containing 3 sections;

The first of the section included nurses' sociodemographic data such as age, marital status, gender, highest education qualification and present rank;

The second section was the adapted version of Maslach Burnout Inventory which measured burnout experience among nurses (11). It is a $22-$ item structured questionnaire that collected quantitative data about burnout experience. Each item measured nurses' experience on a 5 - point likert scale ranging from everyday, once a week, a few times a month, a few times a year to never.

The third section was Karen - personnel instrument for measuring quality (5) which was used to measure the quality of nursing care. It contains 17 items. Each item measured the subjective nurse - reported qualities of nursing care on a 4 - point likert scale ranging from strongly agree, agree, disagree and strongly disagree.

\section{Psychometric properties of the instrument:} this was determined in a pilot study conducted at a healthcare facility in Osogbo. Osogbo is about 35 miles away from Ile - Ife. The pilot study recruited 20 nurses working within the admission facilities of the hospital. The Cronbach's Alpha Coefficients of Maslach Burnout Inventory and Karen-personnel instrument were determined to be 0.757 and 0.843 respectively.

Ethical considerations: Ethical approval for the study was obtained from the SDAH Ethics and Research Committee with protocol number of SERC-2015-001-OS. Permission to collect data was also collected from the management of nursing services of OAUTHC and SDAH. Informed consent was obtained from the nurses. The informed consent addressed issues of confidentiality, anonymity and privacy. No nurse was coerced into participating in the study.

Procedure of Data Collection: While on visit to the research sites, the research instruments were administered by the researcher directly to the nurses, who indicated interest to participate in the study. They were encouraged to complete them at once. The completed instruments were then immediately retrieved and vetted for completeness. The study sites were repeatedly visited until the number of samples was completely reached. During each visit, an identification tally was given to any nurse that had been previously sampled to prevent duplication of data.

Analysis: Maslach's burnout inventory measured all the variables on a five point likert scale. The options of everyday, once a week, a few times a month, a few times a year and never had corresponding scores of 5, 4, 3,2 and 1 . The maximum and minimum scores obtainable by a respondent were 120 and 22 points respectively. Scores obtained by each nurse was computed into percentage and scores below the $25^{\text {th }}$ percentile, between the $25^{\text {th }}$ and $75^{\text {th }}$ percentile and above the $75^{\text {th }}$ percentile were interpreted to mean mild, moderate and severe burnout experiences.

Furthermore, each item on Karen personnel instrument had options of strongly agree, agree, disagree and strongly disagree with corresponding scores of $4,3,2$ and 1 . The maximum and minimum scores obtainable were 68 and 17 points respectively. The score obtained by each nurse was computed into percentage and scores below the $25^{\text {th }}$ percentile, between the $25^{\text {th }}$ and $75^{\text {th }}$ percentile and above the $75^{\text {th }}$ percentile were interpreted to mean low, average and high quality nursing care.

The questionnaires were numbered and data entered into Microsoft Excel for easy sorting. The following a systematic organization and screening was analyzed with SPSS (Statistical Package for Social Sciences) software version 20. Descriptive data were presented with frequency distribution table. Inferential statistics were done with Kruskal - Wallis $\mathrm{H}$ tests at statistical significance of 0.05 .

\section{RESULTS \\ Demographic characteristics of the respondents}

Tables 1 revealed the socio-demographic characteristics of the Nurses studied. Majority of the respondents fell within ages 20 to 30 years $(45.7 \%)$ and were females $(74.8 \%)$ as well as married $(68.3 \%)$. Furthermore, close to half of the respondents had first degree qualification in nursing while about two third of them were within the junior nursing ranks. 


\section{Burnout experiences amongst nurses}

Table 2 revealed that $40 \%$ of the nurses reported severe burnout experience. The mean experience of burnout among nurses in OAUTHC was more than the mean experience among the nurses in SDA hospital however, the difference was not statistically significant $\left(\chi^{2}=0.483, \mathrm{p}=0.487\right)$

\section{Self-reported quality of nursing care}

Table 3 showed that $57.4 \%$ of the nurses rated the quality of nursing care as average. Also, there was no statistically significant difference in the quality of nursing care rendered in both hospitals $\operatorname{studied}\left(\chi^{2}=0.400, p=0.580\right)$.

\section{Burnout experiences versus self - reported quality of nursing care}

There was a statistically significant association between Burnout experiences and the nurse reported quality of nursing care in the hospitals studied $\left(\chi^{2}=14.46, \mathrm{df}=4, \mathrm{p}=0.006\right)$.

\section{DISCUSSION}

The issue of burnout experience has been extensively studied especially among healthcare professionals $(12,13)$. The finding of the study was not in any way different since all the nurses experienced various degrees of burnout. However, majority of the respondents were found out to have a severe burnout experience. This could be because of many of the nurses were younger, married and had a few years of experience. Literature evidences have linked burnout experiences among nurses to younger age and years of experience fewer than five years (14) as well as the stress of work - family conflicts $(15,16)$ including marriage $(17)$.

Furthermore, the burnout experiences of the nurses in the private SDA hospital and government owned OAUTHC was different, although not statistically significant $\left(\chi^{2}=0.483\right.$, p $=0.487)$. This agrees with similar studies which have documented the experience among nurses across all practice settings (18, 19, 20). Moreover, nurses working in the private facility had more intense burnout experience $(x=116.53)$ than their colleagues in the government facility $(x$ $=105.63)$. This may be because of difference in nursing resources availability and utilization for instance, in terms of nursing personnel, the government teaching hospital had more than the private hospital studied, evidenced by a staff ratio difference of $13: 1$. This translates to more working hours and frequent shift duties for the nurses within the private tertiary healthcare facility studied. Staff shortages, long working hours, frequent night shifts among other factors have been blamed for the occurrence of burnout experiences among nurses $(7,21,22)$.

Most of the nurses rated the quality of nursing care they render as average across all the hospitals studied. Findings in literature has been diverse; a study conducted in medical and surgical wards of an Ethiopian hospital rated the overall quality of nursing care as fair (4), while good quality was reported in studies among acute care nurses in Sweden (23) and emergency nurse practitioners in New Zealand (24). The occurrence of burnout among the nurses studied affected the quality of nursing care in the facility studied $\left(\chi^{2}=14.46, \mathrm{p}=0.006\right)$. This finding is congruent to findings in related studies $(8,9,25)$.

\section{CONCLUSION}

The study described occurrence of various degrees of burnout experience among all nurses working within the admission facilities of tertiary healthcare facilities within Osun state. This was due to both individual predisposing factors of the nurses and organizational precipitating factors within the studied facilities. The study also deduced that the burnout experience affected the quality of nursing care delivery in the facilities studied. Factors that contributed to burnout experiences among these nurses require further study.

Limitations: The study acknowledges that narrow scope of the study setting may pose a limitation concerning generalization. The other teaching hospital that qualified to be included in the study could not be studied due to industrial action during the time of the study. Moreover, the analyzed quantitative data on the burnout experiences and quality of nursing care were reported by nurses hence liable to recall bias. Furthermore, the cross - sectional approach to this study may also be of concern. The study therefore cannot establish a causal relationship between burnout and nurse - rated quality of care. Future research should focus on investigating whether burnout directly affects patient care.

\section{Conflicts of interest: No conflict of interest}

\section{REFERENCES}

1. Abosede O B (2015). Assessment of Work related Stress and Coping Strategies among Nurses at Obafemi Awolowo University Teaching Hospitals Complex, Ile Ife. Unpublished dissertation of the Department of Nursing, Obafemi Awolowo University, Ile Ife

2. Li-Pin C, Chung Y, Hu S C (2014). Job Stress and 
Burnout in Hospital Employees: Comparison of different Medical Profession in a Regional Hospital in Taiwan. General Medical Journal, $313-317$.

3. Weber A, Jaekel-Reinhard A (2000). Burnout syndrome: a disease of modern societies $\chi$ Occupational Medicine, 50 (7), 512 - 517.

4. Gerensea, H, Solomon, K, Birhane, M, Medhin, B G, Mariam, T H, Guesh, K, Mekonen, S (2015). Quality of Nursing Care among in-Patient of Medical-Surgical Ward in Axum St. Marry Hospital, Tigray, Ethiopia. Enz Eng, 4 (2). http://dx.doi.org/10.4172/2329-6674.1000132

5. Lindgren M, Andersson I S (2011). Karen Instruments for Measuring Quality in Nursing Care: Construct Validity and Internal Consistency. International Journal for Quality in Healthcare, 3, 292-301.

6. Burhans, L M, Alligood, M R (2010). Quality nursing care in the words of nurses. Journal of Advanced Nursing, 66(8): 1689 - 1697. doi: 10.1111/j.1365-2648.2010.05344.x

7. Laosebikan V O, Oyetunde M O (2012). Burnout among Nurses in Nigerian General Hospital; Prevalence and Associated Factors. Hindawi Publishing Cooperation, 208-214.

8. Shanafelt T D, Bradley K A, Wipf J E, Back A L (2002). Burnout and Self-Reported Patients Care in an Internal Medicine Residency Program. Annals of Internal Medicine, 136(5), 358-367.

9. Poghosyan L, Clark S P, Finlayson M, Aiken L H (2010). Nurses Burnout and Quality of Care: Cross - National Investigation in Six Countries. Research in Nursing and Health, 33 (4), 288 298.

10. Israel G D (1992). Determining Sample Size. University of Florida Fact Sheet, PEOD - 6, Nov. 1992.

11. Maslach C, Jackson S E (1981). The measurement of experienced burnout. Journal of Occupational Behaviour, 2 (2), 99-113.

12. Hinderer K A et al., (2014). Burnout, compassion fatigue, compassion satisfaction, and secondary traumatic stress in trauma nurses. Journal of Trauma Nursing, 21 (4): 160 - 169. doi: 10.1097/JTN.0000000000000055.

13. Young J L, Derr D M, Cicchillo V J, Bressler S (2011). Compassion satisfaction, burnout, and secondary traumatic stress in heart and vascular nurses. Critical Care Nursing, 34 (3), 227 - 234. doi: 10.1097/CNQ.0b013e31821c67d5.

14. Alexander, G K, Rollins K, Walker, D, Wong, L, Pennings, J. (2015). Yoga for self-care and burnout prevention among nurses. Workplace Health \& Safety, 63, (10), 462 - 470 . d o i :

\section{$10.1177 / 2165079915596102$}

15. Glaser W, Hecht, T D (2013). Work-family conflicts, threat-appraisal, self-efficacy and emotional exhaustion. Journal of Managerial Psychology, 28, 164-182.

16. Åhlin, J (2015). Stress of conscience and burnout among healthcare personnel working in residential care of older people. Umeå University Medical Dissertations. Retrieved from http://umu.diva-portal.org/ on 01/02/2018.

17. Pines, A M (1987). Marriage burnout: A new conceptual framework for working with couples. Psychotherapy in Private Practice, 5, 31-44.

18. Oncology Nursing Forum (2016). Compassion Fatigue, Burnout, and Compassion Satisfaction among Oncology Nurses in the United States and Canada. Oncology Nursing Forum, 43 (4), 161 169. DOI : 10.1188/16.ONF.E161-E169

19. Gandi J C, Paul S, Haruna K, Zubaira K D (2011). The Role of Stress and level of Burnout in Job Performance among Nurses. Mental Health in Family Medicine, 8, 181-194.

20. Saini R, Sukhpal K, Karobi D (2011). Assessment of Stress and Burnout among Intensive Care Nurses at a Tertiary Care Hospital. Journal of Mental Health and Human Behaviour, 16 (1), $42-$ 48.

21. Hunsaker S, Hsiu-Chin C, Maughan D, Heaston S (2015). Factors That Influence the Development of Compassion Fatigue, Burnout, and Compassion Satisfaction in Emergency Department Nurses. TOC, 47 (2), 186-194.

22. Kelly L, Runge J, Spencer C (2015). Predictors of Compassion Fatigue and Compassion Satisfaction in Acute Care Nurses. Journal of Nursing Scholarship, 47 (6), 522-528. DOI: 10.1111/jnu.12162

23. Andersson, I S, Lindgren, M (2013). Perceptions of nursing care quality, in acute hospital settings measured by the Karen instruments. Journal of Nursing Management, 21, 87-93. DOI: 10.1111/jonm. 12011

24. Jennings, N, Clifford, S, Fox, A R, O'Connell, J, Gardner, G (2014). The impact of nurse practitioner services on cost, quality of care, satisfaction and waiting times in the emergency department. A systematic review. International Journal of Nursing Studies, 52 (2015), 421 - 435. http://dx.doi.org/10.1016/j.ijnurstu.2014.07.006

25. Azeem S M, Nazir N A, Zaidi Z B A, Akhtar N (2014). Role of Stress and Burnout among nurses in Private Hospitals. International Journal of Academic Research in Business and Social Sciences, 4 (3), 420-428. 
Table 1: Socio-demographic Characteristics of the Nurses

\begin{tabular}{lll}
\hline Variables & $\begin{array}{l}\text { Frequency } \\
=230)\end{array}$ & $\begin{array}{l}(\mathrm{n} \\
(\%)\end{array}$ \\
\hline Age in years & 105 & 45.7 \\
$20-30$ & 76 & 33.0 \\
$31-40$ & 43 & 18.7 \\
$41-50$ & 8 & 2.6 \\
More than 51 & & \\
Gender & 58 & 25.2 \\
Male & 172 & 74.8 \\
Female & & \\
Marital status & 72 & 31.3 \\
Single & 157 & 68.3 \\
Married & 1 & 0.4 \\
Divorced & & \\
Highest Educational Qualification & 102 & 44.4 \\
Diploma & 110 & 47.8 \\
B. N. Sc. & 18 & 7.8 \\
M. Sc. & & \\
Professional Rank & 169 & 73.4 \\
NO I and II & 13 & 5.7 \\
SNO & 35 & 15.2 \\
ACNO and CNO & 13 & 5.7 \\
ADNS & & \\
\hline
\end{tabular}

Table 2: Burnout experiences amongst nurses

\begin{tabular}{|c|c|c|c|c|c|c|}
\hline & \multicolumn{3}{|c|}{ Levels of Burnout Experiences } & \multirow{2}{*}{$\begin{array}{l}\text { Total } \\
(\%)\end{array}$} & \multirow[t]{2}{*}{$\chi^{2}$} & \multirow[t]{2}{*}{$\mathrm{p}$} \\
\hline & Mild & Moderate & Severe & & & \\
\hline Frequency $(\%)$ & 34.6 & 25.4 & 40.0 & 100 & 0.483 & 0.487 \\
\hline
\end{tabular}

Table 3: Nurse - Reported Quality of Nursing Care

\begin{tabular}{|c|c|c|c|c|c|c|}
\hline & \multicolumn{3}{|c|}{ Nurse - Reported Quality of Nursing Care } & \multirow{2}{*}{$\begin{array}{l}\text { Total } \\
(\%)\end{array}$} & \multirow[t]{2}{*}{$\chi^{2}$} & \multirow[t]{2}{*}{$\mathrm{p}$} \\
\hline & Low & Average & High & & & \\
\hline Frequency $(\%)$ & 28.7 & 57.4 & 13.9 & 100 & 0.400 & 0.580 \\
\hline
\end{tabular}

